\title{
Centre for Addiction and Mental Health Inventory of Gambling Situations: Evaluation of the Factor Structure, Reliability, and External Correlations
}

\author{
Nigel E. Turner • Nina Littman-Sharp • Tony Toneatto • \\ Eleanor Liu • Peter Ferentzy
}

Published online: 3 July 2013

(C) Springer Science+Business Media New York 2013

\begin{abstract}
The development and evaluation of the Centre for Addiction and Mental Health Inventory of Gambling Situations (CAMH-IGS) is described. The CAMH-IGS is based on a cognitive-behavioural approach to addiction that sees excessive gambling as a pattern of behaviour which is learned, and which can be changed. The CAMH-IGS is designed to determine the patterns of behaviour, thoughts or feelings which may trigger problematic gambling, with the goal of developing tailored treatment and relapse-prevention approaches for clients. The information can be used in treatment planning. A sample of 524 gamblers that included 323 problem and probable pathological gamblers was used to evaluate the factor structure, reliability, and external correlations of the CAMH-IGS. The results show that the CAMH-IGS consists of 10 internally reliable subscales that can identify individual differences between clients.
\end{abstract}

Keywords Problem gambling · Situational risk · Psychometrics · Confirmatory factor analysis · Relapse prevention

\footnotetext{
N. E. Turner $(\bowtie) \cdot$ N. Littman-Sharp $\cdot$ E. Liu $\cdot$ P. Ferentzy

Centre for Addiction and Mental Health, 33 Russell Street, Toronto, ON CAN M5S 2S1, Canada e-mail: nigel_turner@camh.net

N. Littman-Sharp

e-mail: nina_littman@camh.net

E. Liu

e-mail: Eleanor_Liu@camh.net

P. Ferentzy

e-mail: pferentzy@sympatico.ca

N. E. Turner $\cdot$ T. Toneatto

Department of Public Health Science, University of Toronto, Toronto, Canada

T. Toneatto

e-mail: tony.toneatto@utoronto.ca

T. Toneatto

New College, University of Toronto, Toronto, ON CAN M5S 1C7, Canada
} 
This paper describes the development and evaluation of a measure designed to facilitate treatment planning: the Centre for Addiction and Mental Health Inventory of Gambling Situations (CAMH-IGS) ${ }^{1}$ (Littman-Sharp et al. 2009). The CAMH-IGS is a 63-item selfreport questionnaire that can easily be administered in either online or paper-and-pencil formats. The CAMH-IGS translates the results into an individualized profile detailing situations in which a client has gambled excessively over the past year. The structure and design of the CAMH-IGS is similar to the Inventory of Drinking Situations (IDS) (Annis et al. 1987), and the Inventory of Drug Taking Situations (IDTS) (Turner et al. 1997). The IDS and IDTS were developed based on the pioneering work of Alan Marlatt and his associates (Marlatt 1978, 1979a, 1979b, 1985; Marlatt and Gordon 1980) on situational specific relapse risk. This paper evaluated the psychometric properties of the CAMH-IGS using confirmatory factor analysis, internal reliability, as well as convergent validity and divergent validity.

Gambling disorders have only recently been recognized as an addiction (see Grant 2013). Gambling disorders share many features with substance abuse including similar biological, psychological, and social risk factors (Ferentzy and Turner 2013; Potenza 2008). For the current paper a key similarity is the role of positive and negative reinforcement in the development and/or maintenance of an addiction. Marlatt and Gordon (1980) have argued that a key to helping a client break the cycle of addictions is to understand the nature of the situational factors that contribute to the positive and negative reinforcement of their addiction. The CAMH-IGS was designed to help identify a client's high risk situations and help the client break the cycle. In contrast to screening and diagnostic tools, whose purpose is to detect gambling problems, the CAMH-IGS's role is to identify high risk situations for engaging in the behaviour. This information can be used by a therapist to develop an individualized treatment plan for those affected by problem gambling. Like the IDS, the CAMH-IGS is based on an approach which views excessive gambling as a pattern of behaviour and cognitions which are learned and can thus be changed (see Annis 1990, 1982; Annis and Davis 1989; Annis and Graham 1988, 1995; Annis et al. 1987, 1996a; Annis and Martin 1985). This report was conducted in a manner similar to that used to describe the IDS (Annis 1982), IDTS (Turner et al. 1997) and the Drug Taking Confidence Questionnaire (DTCQ) (Sklar et al. 1997, 1998; Sklar and Turner 1999).

The CAMH-IGS consists of a series of 63 general situations that a problem gambler might encounter. The situations are general enough that most people would either have experienced that situation or could easily imagine being in that situation. Clients are asked to indicate how frequently they gambled heavily in each of the 63 situations, using a 4-point scale ranging from "never" to "almost always". The CAMH-IGS total score indicates an overall global level of situational susceptibility. In addition, the ten subscale scores constitute a gambling profile for each client across the ten categories of gambling situations. The CAMH-IGS provides a systematic profile of the antecedents, or triggers, of a client's problematic gambling behaviour. While many therapists elicit this kind of information in assessment interviews with their clients, the CAMH-IGS offers a simple way to develop an individualized profile of each client's risk situations. In addition, the broad range of situations ensures that a therapist will obtain a more complete picture of the high risk situations for the individual. This information can be used in assessment, treatment planning, relapse prevention, or aftercare planning. Littman-Sharp et al. (2009) include a detailed summary of the use of the CAMH-IGS in clinical settings.

\footnotetext{
${ }^{1}$ Note we originally called our instrument the IGS. However, we recently discovered that another group of authors (Weiss and Petry 2008; Petry et al. 2010), have already used the name IGS. To avoid confusion we have added CAMH to the name. The main difference between the CAMH-IGS and Petry's IGS is that the CAMH-IGS provides more information about gambling specific high-risk situations.
} 
As shown in Table 1, the CAMH-IGS consists of 10 subscales. Six of these subscales - negative emotions (NE derived from the IDTS unpleasant emotions), conflict with others (CO), testing personal control (TPC), pleasant emotions (PE), social pressure (SP), and urges and temptations (UT) - were derived directly from the IDTS (Turner et al. 1997) and DTCQ (Sklar et al. 1997, 1998; Sklar and Turner 1999). In recognition of the unique characteristics of gambling the CAMH-IGS includes four gambling specific subscales: need for excitement (NEX), confidence in skill (CS), winning and chasing (WC), and worried about debts (WD). These scales attempt to capture the idea of being caught in the gambling cycle by following the gambler from initial motivations (e.g., NEX, $\mathrm{CS}$ ), through increasing levels of cognitive entrapment (e.g., WC), to gambling in the hope of paying debts (e.g., WD).

\section{Initial Development}

The design of the CAMH-IGS was based on two previously validated psychometric tools: the IDS (Annis et al. 1987), and the IDTS (Turner et al. 1997). The first version of the CAMH-IGS was developed by Littman-Sharp and Stirpe (1996). The initial pool of items included several items that were borrowed from the IDS (Annis et al. 1987) and IDTS (Turner et al. 1997). In addition, the authors examined the research literature on problem gambling, and the high risk

Table 1 Example items from each of the 10 subscales

\begin{tabular}{|c|c|}
\hline Subscale & Example item \\
\hline Negative emotions (NE) & $\begin{array}{l}\text { (07) When I was depressed. } \\
\text { (37) When I felt under a lot of stress. }\end{array}$ \\
\hline Conflict with others (CO) & $\begin{array}{l}\text { (23) When I had an argument with a friend. } \\
\text { (32) When there were fights at home }\end{array}$ \\
\hline Pleasant emotions (PE) & $\begin{array}{l}\text { (04) When I was happy. } \\
\text { (16) When I felt confident and relaxed. }\end{array}$ \\
\hline Social pressure (SP) & $\begin{array}{l}\text { (30) When someone challenged me to a bet. } \\
\text { (44) When I was in a social situation and other people were gambling. }\end{array}$ \\
\hline Urges and temptations (UT) & $\begin{array}{l}\text { (14) When I was in a situation in which I was in the habit of gambling. } \\
\text { (22) When I suddenly had an urge to gamble. }\end{array}$ \\
\hline Testing personal control (TPC) & $\begin{array}{l}\text { (09) When I started to believe that gambling was no longer a problem } \\
\text { for me. } \\
\text { (47) When I convinced myself that I was a new person and could } \\
\text { make a few bets. }\end{array}$ \\
\hline Need for excitement (NEX) & $\begin{array}{l}\text { (05) When I wanted some action. } \\
\text { (50) When I began to think how exciting or relaxing a little gambling } \\
\text { would be. }\end{array}$ \\
\hline Worried about debts (WD) & $\begin{array}{l}\text { (08) When I was about to get caught unless I came up with some } \\
\text { money fast. } \\
\text { (26) When I was afraid of the people to whom I owed money. }\end{array}$ \\
\hline Winning and chasing (WC) & $\begin{array}{l}\text { (19) When I was winning and wanted to keep on winning. } \\
\text { (46) When I needed to win back the money I lost gambling. }\end{array}$ \\
\hline Confidence in skill (CS) & $\begin{array}{l}\text { (27) When I felt confident about my gambling skills. } \\
\text { (57) When I knew it was a "sure thing." }\end{array}$ \\
\hline
\end{tabular}


classification system was expanded to include situations that were more specific to gambling. The result was a collection of 200 items and seven categories of items.

To establish face and content validity, a group of experts ${ }^{2}$ were asked to rate the usefulness of each item and to place each of the items into one of the seven categories: NE, SP, PE, UT, CO, and TPC and caught in the gambling cycle (Littman-Sharp and Stirpe 1996). Items with low inter-rater reliability or low-rated usefulness were eliminated, reducing the questionnaire to 100 items.

This 100 item version of the CAMH-IGS was used in two studies that were conducted at roughly the same time. One sample was obtained from 233 problem gambling clients receiving clinical services who completed the 100-item version of the CAMH-IGS and the South Oaks Gambling Screen (SOGS-R) as part of their assessment (Littman-Sharp 1997, Unpublished raw data). A second set of data was available from a multi-centre treatment outcome study conducted by Tony Toneatto comprising 197 individuals (Toneatto 1997, Unpublished raw data). After a thorough check, 26 lines of data were removed because the same participants were included in both sets of data bringing the total data available to 404 participants. The average SOGS-R score for the first sample was $11.4(\mathrm{SD}=4.8)$ and the average score for the second was 13.4 ( $\mathrm{SD}=4.1)$. In total, the sample consisted of 307 males and 98 females ranging in age from 17 to 74 .

Factor analysis was conducted in both data sets separately and then the two were compared. Each sample indicated several eigenvalues greater than 1, but 10 clusters of variables were found in both samples. These 10 clusters of items formed the basis of the subscales of the revised CAMH-IGS. Items that clustered consistently in the two samples were selected. Items that were poorly worded or redundant were deleted. Items that did not load on any factor were also deleted. Factors that consisted of too many items were pared down to those items that were loaded highly on one subscale and had small secondary loadings. Reliability analyses were conducted for each tentative subscale and items with low reliability were deleted. Using these methods, the questionnaire was reduced from 100 to 58 items. The combined sample of 404 was adequate to assess the factor structure of a 58-item scale (MacCallum et al. 1999, 2001). A scree plot analysis identified discontinuities after 7 factors and after 10 factors. Analysis with more than 10 factors did not yield additional interpretable factors. Five of the original subscales were found in the data: NE, CO, TPC, SP, and UT. The caught in the gambling cycle items did not form a single cluster but broke into four clusters of items with well-defined loading patterns. These were labeled: NEX, WD, WC and CS. Only 2 items on the PE subscale clustered together. To correct this problem, 5 new items were created based on the PE and pleasant times with others subscales of the IDTS (Turner et al. 1997) thus bringing the revised CAMH-IGS to 63 items.

The content validity of the 63-item version of the CAMH-IGS was then evaluated by Turner and McKenzie (Turner and McKenzie 2001, Unpublished raw data) using focus group interviews with problem gambling counsellors and individual interviews with problem gamblers. The results of these interviews was positive feedback regarding the inclusiveness of the CAMH-IGS from both types of interviews. A total of 19 pathological gamblers from the CAMH problem gambling service were individually interviewed about their gambling. As part of the interview the participants were asked to verbally describe the situations in which they gambled problematically. Their descriptions were coded based on

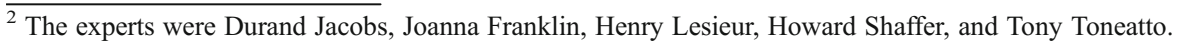


the CAMH-IGS categories or other categories as needed. Participants scored an average of $49(\mathrm{SD}=28)$ on subscales that were similar to the topics that they mentioned in the interviews as being problematic, but only $29(\mathrm{SD}=17)$ on subscales they did not mention during the interview, $\mathrm{t}(19)=5.6, p<.001, d=1.3$. More importantly, analysis of the participants' responsees did not indicate any major areas of concern that were not covered in the CAMH-IGS.

The revised CAMH-IGS with 63 items was then included in three separate but related studies conducted by Turner and Toneatto. These studies were conducted for a number of reasons including the cross-validation of the CAMH-IGS.

In the current paper the data from these three studies has been combined in order to use confirmatory factor analysis to confirm the factorial validity of the CAMH-IGS. The reason for combining the data is that confirmatory factor analysis requires a large sample size. In addition, the paper will examine correlations of the CAMH-IGS subscales with a variety of external variables in order to determine the convergent and divergent validity of the CAMH-IGS. The IGS total score is linked to overall level of situational risk; a person who responds to more situations in general has a more severe gambling problem. Thus the overall IGS score should be correlated with measures of gambling problem severity.

Various external measures were used to validate the differences between the subscales. In this study, to validate the different subscales we included external variables that were conceptually related to some specific subscales (convergent) and not related to other specific subscales (divergent). For example, depression is more strongly related to NE and $\mathrm{CO}$ than to $\mathrm{PE}$ and therefore should show convergent validity by being strongly correlated with $\mathrm{NE}$ and $\mathrm{CO}$, and show divergent validity by being unrelated to PE. In addition measures of impulsivity, erroneous beliefs, and beliefs about skill were included to test the validity of UT, WC, and CS respectively.

Based on previous research with the IDTS and DTCQ (Annis et al. 1996b, 1996c; Sklar et al. 1998; Turner et al. 1997) the following hypotheses were made:

(1) The factor structure of the CAMH-IGS will be confirmed.

(2) Each subscale will show adequate reliability $(>.70)$.

(3) Gamblers with more severe problems will score higher on the CAMH-IGS indicating convergent validity.

(4) Several specific measures were included to measure the convergent and divergent validity of different subscale: If these hypotheses are confirmed it would mean that the CAMH-IGS subscales can indicate differences between individuals.

(4a) NE and CO are conceptually related to negative affect and should be significantly correlated to depression and anxiety.

(4b) PE measures gambling when happy and therefore should not be correlated with depression or anxiety but should still be correlated with problem severity.

(4c) UT measures impulsive susceptibility to temptation and should be most strongly related to impulsivity.

(4d) WC measures trying to win back what has been lost, and should be significantly correlated with measure of erroneous beliefs.

(4e) CS measures belief in one's own level of skill and therefore should be most strongly related to the use of strategies and systems while gambling.

(5) Based on previous research with the IDTS and DTCQ (Annis et al. 1996b, 1996c; Sklar et al. 1998) females may score higher than males on NE.

(6) The different samples will be similar in spite of the different data collection methods. 


\section{Method}

Participants

The data for this paper was collected in three different but related studies (see below). The total sample size was 524. This sample size is sufficient for the type of analysis that is conducted in this paper given the sample size, the number of items and the commonalities between items (see MacCallum et al. 1999, 2001). Assessment of gambling problems was conducted using the SOGS-R (Lesieur and Blume 1987, 1993) and the Diagnostic and Statistical Manual of Mental Disorders (DSM-IV-TR; American Psychiatric Association 2000). The sample included 259 probable pathological gamblers (greater than or equal to 5 on SOGS-R or DSM-IV-TR), 208 non-problem gamblers (less than or equal to 2 on both SOGS-R and DSM-IV-TR) and 64 sub-clinical problem gamblers (greater than 2 and less than 5 on SOGS-R and DSM-IV-TR). Participants had to be at least 18 years of age and actively involved in some form of gambling (at least once per month). In all three studies, the participants were recruited using newspaper ads, advertisements at our treatment centre (new clients only), and snowball techniques wherein each participant was asked to refer other problem gamblers to the study. Although all three studies used the same methods, sample 1 emphasized recruitment through the treatment centre more and sample 3 emphasized newspaper ads more. The participants contacted the research team using a 1-800 number.

Sample one (Turner and Toneatto 1999, Unpublished raw data; Turner et al. 2011) was collected as part of an examination of erroneous beliefs about gambling $(N=131)$. People who called the 1-800 number were invited to CAMH for an interview and questionnaire. A total of Can $\$ 10$ in gift certificates was paid to all participants.

Sample two (Turner and Toneatto 2001, Unpublished raw data) was a study of the distribution of gambling problems, impulsivity, depression, and erroneous beliefs within a family that was conducted by mail $(n=253)$. Participants were asked about their own gambling and the gambling habits of other people in their families (mother, father, sister, brother). A package containing the questionnaires and a self-addressed envelope was mailed out to participants who had contacted us through the 1-800 number. Some participants received up to 4 different questionnaire packages over a span of several months. The CAMH-IGS was only included in the first package mailed out to the participants. The participants were paid Can $\$ 10$ for each completed questionnaire package that they returned to us.

Sample three (Turner et al. 2008) was collected as part of a study of the risk factors associated with the severity of problem gambling $(n=140)$. People who called the $1-800$ number were invited to the $\mathrm{CAMH}$ for an interview, questionnaire, and blood test. The participants completed a large battery of questionnaires, some experimental procedures, and had a blood sample taken to measure genetic risk. The study took 2 to $3 \mathrm{~h}$ to complete and the participants were paid Can $\$ 100$.

By design, there was considerable overlap in the questionnaires used in these three studies, and their data was combined together; however, some variables were only present in one or two studies. During recruitment it was ensured that none of the participants were included in more than one study.

\section{Design and Procedure}

Each project was reviewed and approved by the CAMH ethics review board and the authors complied with American Psychological Association ethical standards in the treatment of human participants. 
These three studies used a correlational design. Purposive sampling was utilised for sample selection. Potential participants were recruited through newspaper advertisements asking for "social gamblers" or advertisements distributed to the CAMH problem gambling treatment service. Participants had to be at least 18 years of age and actively involved in some form of gambling (at least once per month). Based on past recruitment efforts, this strategy has been shown to be an efficient and inexpensive means of recruiting both nonproblem social gamblers and probable pathological gamblers (Turner et al. 2006). People called the advertised toll free number and left their phone numbers on voice mail.

For samples 1 and 3, participants were invited into the office to complete the questionnaires. The researcher sat in an adjoining room and was available for questions. For sample 2, the CAMH-IGS questionnaire was one of the questionnaires mailed out to the participants with a self-addressed envelope. The researcher was available by telephone to answer any questions.

After the session ended (or the questionnaire package was returned), all participants were provided with information about problem gambling and treatment services. The debriefing form stated clearly that the information was provided to all participants regardless of whether they had a problem in order to raise awareness about problem gambling and the availability of treatment services.

\section{Measures}

To test hypothesis 1 , the 63 item CAMH-IGS was included in all three samples.

In order to test hypothesis 3 severity of problem gambling was assessed using the SOGSR (Lesieur and Blume 1987, 1993), and the 10 item DSM-IV-TR criteria for pathological gambling (American Psychiatric Association 2000) was used as a self-report scale (al$p h a=.87)$. Numerous studies have shown that the SOGS-R is a valid and reliable instrument for assessing problem and pathological gambling (e.g., Lesieur and Blume 1987, 1993). The SOGS-R was framed in terms of the "past 12 months" (alpha=.92). The version of the DSMIV-TR that was used has also been used in several studies (e.g., Room et al. 1999; Turner et al. 2006, 2008, 2009), has been highly correlated with the SOGS-R (e.g., .8 to .9) and has a high degree of reliability (alpha=.87). These two scales were included in all three studies.

In order to test hypothesis $4 \mathrm{a}(\mathrm{NE} \& \mathrm{CO}$ related to depression \& anxiety) and hypothesis $4 \mathrm{~b}$ (PE unrelated to depression and anxiety) samples 2 and 3 included an assessment of current depression (i.e., Center for Epidemiologic Studies Depression Scale CES-D, Radloff 1977; see also Robinson et al. 1991) and a measure of social anxiety (Leary 1983; see also Robinson et al. 1991). In order to test hypothesis 4c (UT related to impulsiveness) samples 2 and 3 included an assessment of impulsiveness (Barrat 1987).

To test hypothesis 4d (WC and erroneous beliefs) and 4e (CS and strategies) samples 2 and 3 included the Random Event Knowledge Test (REKT; Turner and Liu 1999; Turner et al. 2006) to assess erroneous beliefs and samples 1 and 2 included Toneatto's (1998) Gambling Cognitions Questionnaire (GCQ). The REKT measures a participant's understanding of the nature of random chance and therefore should be negatively related to the WC scale. Past research indicates that the REKT has adequate reliability $($ alph $a=.70)$ and is negatively related to problem gambling with an effect size ranging from $r=-.20$ to $r=-.35$ (Turner and Liu 1999; Turner et al. 2006, 2008; Preston et al. 2012).

The Gambling Cognitions Questionnaire, (Toneatto 1998) was included in samples 1 and 2 as a measure of erroneous beliefs and cognitive distortions. This scale was derived from Toneatto's research into different types of beliefs held by gamblers about how to win (Toneatto et al. 1997; Turner and Liu 1999). The questions cover topics such as beliefs about luck, the belief that 
persistence (e.g., chasing) pays off, and perceived skills. Previous research has shown that this scale is a reliable and valid measure of erroneous beliefs (Turner and Liu 1999). Two subscales are of particular relevance to the current study: persistence, which measures the belief that persistence must pay off should be most strongly related to WC (hypothesis 4d); and systems, which measures the gamblers reliance on gambling systems and should be most strongly related to CS (hypothesis 4e).

In addition, sample 3 included the Temperament and Character Inventory (TCI; Cloninger et al. 1994) to measure personality. The TCI is a 240 -item self-administered questionnaire that uses "True" or "False" format. The TCI maintains strong theoretical and empirical links to psychobiological models of behaviour (Kose 2003), but is designed for clinical use. It consists of 7 major subscales, which have been shown to be reliable and valid (Cloninger et al. 1994; Kose 2003). Two TCI subscales were of interest in (1) harm avoidance which is related to anxiety and depression (hypothesis 4a), and novelty seeking which is related to impulsiveness (hypothesis $4 \mathrm{c}$ ).

\section{Confirmatory Factor Analysis Set Up}

Confirmatory factor analysis was used because the CAMH-IGS was designed to measure specific theoretical concepts. A confirmatory factor analysis involves fitting a theoretical model to the data. The analysis used LISREL 8 to determine if the items clustered onto factors as expected (Jöreskog and Sörbom 1993). All models were estimated using the generalized least squares estimation. The confirmatory factor analysis reported below used Spearman correlations. Spearman correlations are designed for ordinal data and are stable to variations in distribution (e.g., skew). Another option would have been polychoric correlation matrix (PM). However, a PM matrix requires a very large sample size in order to compute an accurate asymptotic weight matrix (Jaccard and Wan 1995). A PM analysis can produce highly inflated estimates with skewed variables (Turner 1997), unless the sample is very large.

\section{Results}

\section{Confirmatory Factor Analysis (Hypothesis 1)}

No major contradictions of the theoretical model were found. After determining that the model was a rough fit to the data, the program was set to conduct an automatic respecification search in which, after each analysis, the parameter with the largest modification index score is set free and the model is run again. The analysis was run until all parameters with a chi-square change greater than 14 were set free (see Table 2). A chi-square of 14 with $1^{\circ}$ of freedom is highly significant; however, the actual parameter change related to such an effect is trivial (e.g., a correlated residual of.04) so that such effects have little impact on the theoretical model. In total the respecification search ran for 16 cycles.

An examination of the modification index and expected changes indicated only small and moderate correlated residuals (e.g., $r<.20)$ and no concentrated clusters of correlated residuals that would suggest additional factors. During the respecification search (see Table 2) only one primary loading was not significant (item 32 on The $\mathrm{CO}$ scale), and two secondary loading were not significant (items 33 on the $\mathrm{CO}$ scale and item 53 on the NE scale). In addition, two items on the CO scale had larger loadings on the NE scale than on the CO scale. Finally, as shown in Table 3, only one new loading was added to the model (item 32 on the NE scale). In summary, there were few changes to the model suggested by this analysis. 
Table 2 Goodness of fit indices for each stage of the automated respecification search

\begin{tabular}{|c|c|c|c|c|c|c|c|c|c|}
\hline \multicolumn{7}{|c|}{ Model fit test statistics } & \multicolumn{3}{|c|}{ Change made to model } \\
\hline Step & df & chi-square & chi-square/df & RMSEA & GFI & NNFI & Matrix & Element & chi-square change \\
\hline 1 & 1718 & 3345.5 & 1.95 & 0.043 & 0.79 & 0.990 & - & - & - \\
\hline 2 & 1717 & 3316.8 & 1.93 & 0.042 & 0.792 & 0.990 & TD & $(57,4)$ & 28.7 \\
\hline 3 & 1716 & 3294.8 & 1.92 & 0.042 & 0.793 & 0.991 & $\mathrm{TD}$ & $(54,49)$ & 22.0 \\
\hline 4 & 1715 & 3272.9 & 1.91 & 0.042 & 0.795 & 0.991 & $\mathrm{TD}$ & $(53,2)$ & 22.0 \\
\hline 5 & 1714 & 3251.6 & 1.90 & 0.041 & 0.796 & 0.991 & $\mathrm{TD}$ & $(26,15)$ & 18.4 \\
\hline 6 & 1713 & 3232.7 & 1.89 & 0.041 & 0.797 & 0.991 & $\mathrm{TD}$ & $(25,5)$ & 18.8 \\
\hline 7 & 1712 & 3214.3 & 1.88 & 0.041 & 0.798 & 0.991 & $\mathrm{TD}$ & $(53,20)$ & 18.4 \\
\hline 8 & 1711 & 3185.8 & 1.86 & 0.041 & 0.800 & 0.991 & LX & $(11,1)$ & 28.5 \\
\hline 9 & 1710 & 3169.4 & 1.85 & 0.040 & 0.801 & 0.991 & TD & $(29,23)$ & 16.4 \\
\hline 10 & 1709 & 3150.7 & 1.84 & 0.040 & 0.802 & 0.991 & TD & $(54,5)$ & 18.7 \\
\hline 11 & 1708 & 3132.3 & 1.83 & 0.040 & 0.804 & 0.991 & $\mathrm{TD}$ & $(49,27)$ & 18.5 \\
\hline 12 & 1707 & 3117.5 & 1.83 & 0.040 & 0.805 & 0.991 & $\mathrm{TD}$ & $(43,23)$ & 14.8 \\
\hline 13 & 1706 & 3102.6 & 1.82 & 0.040 & 0.805 & 0.992 & TD & $(29,20)$ & 14.9 \\
\hline 14 & 1705 & 3088.1 & 1.81 & 0.039 & 0.806 & 0.992 & $\mathrm{TD}$ & $(16,5)$ & 14.5 \\
\hline 15 & 1704 & 3073.6 & 1.80 & 0.039 & 0.807 & 0.992 & $\mathrm{TD}$ & $(25,4)$ & 14.5 \\
\hline 16 & 1703 & 3058.6 & 1.80 & 0.039 & 0.808 & 0.992 & $\mathrm{TD}$ & $(56,6)$ & 15.0 \\
\hline
\end{tabular}

$d f$ degrees of freedom for the chi-square analysis; RMSEA root mean square of approximation; GFI goodness of fit; NNFI non-normed fit index; TD refers to correlated residuals and LX refers to the loading of an item on a subscale; change in chi-square $=$ chi-square at step $\mathrm{x}-1$ minus chi-square at step $\mathrm{x}$

For the 10 factor model the final model had a chi-square $=3058.6(\mathrm{df}=1703)$. The ratio of chisquare to degrees of freedom was 1.80 suggesting that the model accounted for most of the variance. This is also supported by the non-normed fit index score which was .992 and indicates a close fit with the data. The non-normed fit index like other fit indices ranges from 0 to 1 with 1 indicating a very close fit. It has been shown to be less negatively affected by larger sample sizes than other fit indices (Marsh et al. 1988). In addition the root mean error of approximation was 0.039 which indicates that the average squared error in the model was small. The goodness of fit score, .808, was rather low but this is often the case with scales that include large numbers of items (see Marsh et al. 1988; Turner et al. 1997). Overall these fit indices are within the range of good fitting models (Byrne 1989). Table 2 shows the changes in chi-square associated with the respecification search and the parameters that were freed during the respecification search. What is important here is that there were no changes that undermined the 10 factor model of the IGS.

Table 3 shows the factor structure of the CAMH-IGS based on the final analysis for the 10 factor model showing the loadings of the items onto their respective subscales. The main items on each factor form neat clusters of correlations in a diagonal line down the page. A small number of other loadings are scattered over the matrix indicating the cross loadings.

\section{Reliability and Subscale Factor Structure (Hypothesis 2)}

Table 4 shows the Cronbach alpha statistics for each of the subscales. An Alpha of .7 is often cited as adequate reliability (George and Mallery 2003; Nunnally 1978). As shown in Table 4, the lowest alpha was for CS, which had an alpha of .86. This confirms hypothesis 2 and indicates that each of the CAMH-IGS subscales is reliable. 
Table 3 Factor structure of the 10 factor model (LAMBDA-X). Factor structure of the 10 factor model (LAMBDA-X) from the final output from LISREL

\begin{tabular}{ccc}
\hline Item & $\mathrm{NE}$ & $\mathrm{CO}$ \\
\hline \multicolumn{3}{c}{ Negative emotions } \\
7 & 0.79 & - \\
11 & 0.73 & - \\
21 & 0.76 & - \\
34 & 0.72 & - \\
37 & 0.76 & - \\
41 & 0.80 & - \\
51 & 0.80 & - \\
54 & 0.70 & -
\end{tabular}

Conflict with others

$\begin{array}{lll}13 & - & 0.67 \\ 23 & -- & 0.65 \\ 32 & 0.61 & 0.05 \\ 43 & - & 0.66 \\ 61 & 0.54 & 0.21 \\ 63 & - & 0.71\end{array}$

Need for excitement

$\begin{array}{llll}5 & - & - & 0.75 \\ 50 & & - & 0.78 \\ 52 & - & - & 0.82 \\ 55 & - & - & 0.77\end{array}$

Testing personal control

$\begin{array}{lllll}9 & - & - & - & 0.74 \\ 24 & - & - & - & 0.68 \\ 25 & - & - & - & 0.71 \\ 36 & - & - & - & 0.57 \\ 47 & - & - & - & 0.78 \\ 48 & - & - & - & 0.74 \\ 56 & - & - & - & 0.75\end{array}$

Pleasant emotions

\begin{tabular}{|c|c|c|c|c|c|c|}
\hline 4 & - & - & - & - & 0.67 & - \\
\hline 16 & - & - & - & - & 0.75 & - \\
\hline 28 & - & - & - & - & 0.78 & - \\
\hline 38 & - & - & - & - & 0.64 & - \\
\hline 49 & - & - & - & - & 0.48 & 0.26 \\
\hline \multicolumn{7}{|c|}{ Social pressure } \\
\hline 6 & - & - & - & - & - & 0.69 \\
\hline 18 & - & - & - & - & - & 0.64 \\
\hline 20 & - & - & - & - & - & 0.47 \\
\hline 30 & - & - & - & - & - & 0.60 \\
\hline 44 & - & - & 0.31 & - & - & 0.44 \\
\hline 58 & - & - & - & - & - & 0.77 \\
\hline
\end{tabular}


Table 3 (continued)

\begin{tabular}{|c|c|c|c|c|c|c|c|c|c|c|}
\hline Item & $\mathrm{NE}$ & $\mathrm{CO}$ & NEX & $\mathrm{TPC}$ & $\mathrm{PE}$ & $\mathrm{SP}$ & DB & WC & SK & UT \\
\hline \multicolumn{11}{|c|}{ Worried about debts } \\
\hline 8 & - & - & - & - & - & - & 0.72 & - & - & - \\
\hline 26 & - & - & - & - & - & - & 0.63 & - & - & - \\
\hline 29 & - & - & - & - & - & - & 0.38 & - & - & - \\
\hline 39 & - & - & - & - & - & - & 0.75 & - & - & - \\
\hline 60 & - & - & - & - & - & - & 0.72 & - & - & - \\
\hline \multicolumn{11}{|c|}{ Winning and chasing } \\
\hline 1 & - & - & - & - & - & - & - & 0.78 & - & - \\
\hline 19 & - & - & - & - & - & - & - & 0.73 & - & - \\
\hline 33 & - & -0.07 & - & - & - & - & - & 0.82 & - & - \\
\hline 45 & - & -- & 0.20 & - & - & - & - & 0.51 & - & - \\
\hline 46 & - & - & - & - & - & - & - & 0.81 & - & - \\
\hline 59 & - & - & - & - & - & - & - & 0.82 & - & - \\
\hline \multicolumn{11}{|c|}{ Confidence in skill } \\
\hline 3 & - & - & - & - & - & - & - & - & 0.74 & - \\
\hline 15 & - & - & - & - & - & - & - & - & 0.75 & - \\
\hline 27 & - & - & - & - & - & - & - & - & 0.77 & - \\
\hline 40 & - & - & - & - & - & - & - & - & 0.74 & - \\
\hline 57 & - & - & - & - & - & - & - & - & 0.73 & - \\
\hline \multicolumn{11}{|c|}{ Urges and temptations } \\
\hline 12 & - & - & - & - & - & - & - & - & - & 0.77 \\
\hline 14 & - & - & - & - & 0.32 & - & - & - & - & 0.50 \\
\hline 17 & - & - & - & - & - & - & - & - & - & 0.77 \\
\hline 22 & - & - & - & - & - & - & - & - & - & 0.80 \\
\hline 31 & - & - & - & - & - & - & - & - & - & 0.77 \\
\hline 35 & - & - & - & - & - & - & - & - & - & 0.76 \\
\hline 42 & - & - & - & - & - & - & - & - & - & 0.74 \\
\hline 53 & 0.08 & - & - & - & - & - & - & - & - & 0.75 \\
\hline 62 & - & - & - & - & - & - & - & - & - & 0.79 \\
\hline
\end{tabular}

Loadings of less than \pm .1 are not significant. Loadings of $.20 \& .21$ are significant at $p<.01$; all other loadings $p<.001$

This assessment was further strengthened by an examination of the factor structure of each of the subscales. The items for each of the 10 subscales were entered into 10 separate factor analyses. In each case only one eigenvalue was greater than 1 and the first eigenvalue accounted for half or more of the covariance between the items suggesting that all of the subscales were unifactorial. The percentage of variance accounted for by the first factor is shown in Table 4. Taken together these results indicate that for each of the 10 subscales the items appear to form stable reliable factors with good internal consistency.

Convergent Validity (hypothesis 3)

The next step was to validate the convergent validity of the CAMH-IGS (hypothesis 3 ). The CAMH-IGS measures situational risk for heavy gambling. Although not intended as a 
Table 4 Cronbach alpha scores and variance accounted for by first factor for CAMH-IGS subscales $(N=524)$

\begin{tabular}{lll}
\hline Subscale & Alpha & First factor \\
\hline Negative emotions & 0.95 & $70.9 \%$ \\
Conflict with others & 0.92 & $72.1 \%$ \\
Urges and temptations & 0.93 & $66.6 \%$ \\
Testing personal control & 0.90 & $62.0 \%$ \\
Pleasant emotions & 0.90 & $70.8 \%$ \\
Social pressure & 0.86 & $54.6 \%$ \\
Need for excitement & 0.91 & $71.2 \%$ \\
Worried about debts & 0.88 & $68.1 \%$ \\
Winning and chasing & 0.90 & $71.2 \%$ \\
Confidence in skill & 0.90 & $68.6 \%$ \\
Total (all items) & 0.98 & \\
\hline
\end{tabular}

diagnostic measure of pathological gambling, it is clear that a person who gambles problematically should score higher on the CAMH-IGS than someone who does not gamble problematically. As shown in Table 5, all of the CAMH-IGS subscales were correlated with DSM-IV-TR and SOGS-R. The strongest correlations were between the DSM-IV-TR and $\mathrm{UT}, r=.74$, WC, $r=.76$, and NE, $r=.76$.

Convergent and Divergent Validity of the Subscales (Hypothesis 4a to 4e)

A number of variables were included in each of the studies to measure individual differences amongst gamblers (see Tables 6,7 and 8). All of the IGS subscales and many of these external variables are related to the severity of problem gambling. In order to determine how well the CAMH-IGS sub-scales differentiated between different gamblers, partial correlations were computed statistically controlling for DSM-IV-TR and SOGS-R scores using the partial correlation procedure available in SPSS. In some cases both the correlation ( $r$ ) and partial correlation $\left(r_{p}\right)$ are given.

Consistent with hypothesis $4 \mathrm{a}$, depression was most strongly correlated with NE, $r=.47$, $p<.001$, and $\mathrm{CO}, r=.51, p<.001$. After controlling for severity, the partial correlations of

Table 5 Correlations (rho) between CAMH-IGS Subscales, DSM-IV and SOGS-R $(N=524)$

All correlations are significant at the 0.001 level (2-tailed)

\begin{tabular}{lll}
\hline CAMH-IGS Subscale & DSM-IV Total & SOGS-R past year \\
\hline Negative emotions & 0.76 & 0.74 \\
Conflict with others & 0.70 & 0.69 \\
Urges and temptations & 0.74 & 0.72 \\
Testing personal control & 0.70 & 0.67 \\
Pleasant emotions & 0.54 & 0.51 \\
Social pressure to use & 0.57 & 0.58 \\
Need for excitement & 0.68 & 0.66 \\
Worried about debts & 0.68 & 0.71 \\
Winning and chasing & 0.76 & 0.75 \\
Confidence in skill & 0.62 & 0.61 \\
TOTAL CAMH-IGS & 0.78 & 0.75 \\
\hline
\end{tabular}


Table 6 Partial correlations of the CAMH-IGS with depression, impulsivity, social anxiety and random events knowledge (REKT) controlling for DSM-IV and SOGS-R scores

\begin{tabular}{lllll}
\hline & Impulsivity & Depression & Social anxiety & REKT \\
\hline Negative emotions & $0.30^{* * *}$ & $0.34^{* * *}$ & $0.26^{* * *}$ & -0.01 \\
Conflict with others & $0.20^{* *}$ & $0.30^{* * *}$ & $0.18^{* *}$ & -0.05 \\
Urges and temptations & $0.31^{* * *}$ & $0.26^{* * *}$ & $0.19^{* *}$ & 0.07 \\
Testing personal control & $0.16^{*}$ & 0.10 & 0.11 & -0.07 \\
Pleasant emotions & $0.16^{*}$ & 0.07 & 0.06 & 0.03 \\
Social pressure & $0.19^{*}$ & 0.14 & 0.02 & -0.07 \\
Need for excitement & $0.24^{*}$ & $0.17^{*}$ & 0.09 & -0.02 \\
Worried about debts & 0.05 & $0.23^{* * *}$ & $0.16^{*}$ & -0.05 \\
Winning and chasing & $0.18^{*}$ & $0.29^{* * *}$ & $0.20^{* *}$ & $-0.15^{*}$ \\
Confidence in skill & 0.12 & 0.10 & 0.08 & -0.01 \\
CAMH-IGSTOT & $0.27^{* * *}$ & $0.26^{* * *}$ & $0.18^{*}$ & -0.03 \\
\hline
\end{tabular}

Sample size was 245 for REKT, but 193 for the other variables

$* p<.05 ; * * p<.01 ; * * * p<.001$

depression with these two subscales was $\mathrm{r}_{\mathrm{p}}=.34, p<.001$ and $\mathrm{r}_{\mathrm{p}}=.30, p<.001$ respectively thus supporting hypothesis $4 \mathrm{a}$. There were also significant correlations between depression and $\mathrm{UT}, \mathrm{r}_{\mathrm{p}}=.26, p<.001$ and $\mathrm{WC}, \mathrm{r}_{\mathrm{p}}=.29, p<.001$. Social anxiety was also most strongly related to the negative situations including NE, $\mathrm{r}_{\mathrm{p}}=.26, p<.001, \mathrm{CO}, \mathrm{r}_{\mathrm{p}}=.26, p<.001$ and $\mathrm{WD}, \mathrm{r}_{\mathrm{p}}=.26$, $p<.001$. Notably, as hypothesized (hypothesis $4 \mathrm{~b}$ ) the partial correlation for depression and social anxiety with $\mathrm{PE}$ was not significant providing divergent validity between $\mathrm{PE}$ and the negative affect scales (CO \& NE).

Consistent with hypothesis $4 \mathrm{c}$, impulsivity was most strongly correlated with UT, $r=.44$, $p<.001$. In addition impulsivity was also correlated with NEX, $r=.40, p<.001$. After controlling

Table 7 Partial correlations with gambling cognition questions controlling for DSM-IV and SOGS-R scores $(n=384)$

\begin{tabular}{llllllll}
\hline & Persistence & $\begin{array}{l}\text { Positive } \\
\text { attitude }\end{array}$ & $\begin{array}{l}\text { Thinking of } \\
\text { rewards }\end{array}$ & Rituals & Systems & $\begin{array}{l}\text { Favorite } \\
\text { places }\end{array}$ & $\begin{array}{l}\text { Favourite } \\
\text { numbers }\end{array}$ \\
\hline Negative emotions & $0.24^{* * *}$ & $0.13^{*}$ & $0.20^{* * *}$ & $0.29^{* * *}$ & 0.04 & $0.18^{* *}$ & $0.15^{* *}$ \\
Conflict with others & 0.08 & 0.00 & $0.16^{* * *}$ & $0.25^{* * *}$ & 0.05 & 0.10 & $0.11^{*}$ \\
Urges and temptations & $0.25^{* * *}$ & $0.23^{* * *}$ & $0.19^{* * *}$ & $0.28^{* * *}$ & $0.14^{* *}$ & $0.22^{* * *}$ & $0.13^{* *}$ \\
Testing personal control & $0.26^{* * *}$ & $0.15^{* *}$ & $0.12^{*}$ & $0.28^{* * *}$ & $0.13^{*}$ & $0.16^{* * *}$ & $0.20^{* * *}$ \\
Pleasant emotions & $0.23^{* * *}$ & $0.35^{* * *}$ & $0.13^{*}$ & $0.27^{* * *}$ & $0.21^{* * *}$ & $0.33^{* * *}$ & $0.19^{* * *}$ \\
Social pressure & $0.20^{* * *}$ & $0.19^{* *}$ & $0.13^{*}$ & $0.29^{* * *}$ & $0.10^{*}$ & $0.25^{* * *}$ & $0.24^{* * *}$ \\
Need for excitement & $0.28^{* * *}$ & $0.30^{* * *}$ & $0.16^{* *}$ & $0.33^{* * *}$ & $0.18^{* * *}$ & $0.31^{* * *}$ & $0.17^{* * *}$ \\
Worried about debts & $0.11^{*}$ & 0.09 & $0.14^{* *}$ & $0.14^{* *}$ & 0.05 & 0.09 & 0.06 \\
Winning and chasing & $0.36^{* * *}$ & $0.21 * * *$ & $0.21^{* * *}$ & $0.33^{* * *}$ & $0.13^{* *}$ & $0.22^{* * *}$ & $0.20^{* * *}$ \\
Confidence in skill & $0.34^{* * *}$ & $0.38^{* * *}$ & $0.23^{* * *}$ & $0.27 * * *$ & $0.45^{* * *}$ & $0.26^{* * *}$ & $0.19^{* * *}$ \\
CAMH-IGSTOT & $0.32^{* * *}$ & $0.27^{* * *}$ & $0.22^{* * *}$ & $0.37^{* * *}$ & $0.21^{* * *}$ & $0.28^{* * *}$ & $0.22^{* * *}$ \\
\hline
\end{tabular}

$* p<.05 ; * * p<.01 ; * * * p<.001$ 
Table 8 Partial correlations of the TCI and the CAMH-IGS subscales controlling for DSM-IV and SOGS-R scores $(n=140)$

\begin{tabular}{llllllll}
\hline & NS & HA & RD & PS & SD & CO & ST \\
\hline Negative emotions & 0.04 & $0.22^{* *}$ & -0.02 & -0.02 & -0.12 & -0.10 & -0.04 \\
Conflict with others & 0.01 & $0.16^{*}$ & -0.09 & -0.07 & $-0.17^{*}$ & $-0.20^{*}$ & 0.04 \\
Urges and temptations & 0.11 & $0.20^{*}$ & 0.00 & 0.01 & -0.08 & -0.05 & -0.04 \\
Testing personal control & 0.01 & $0.17^{*}$ & -0.01 & -0.11 & -0.14 & -0.04 & 0.11 \\
Pleasant emotions & 0.02 & -0.07 & 0.11 & 0.07 & 0.05 & -0.04 & 0.08 \\
Social pressure & 0.07 & -0.03 & 0.02 & $0.19 *$ & -0.01 & -0.09 & 0.09 \\
Need for excitement & 0.11 & 0.08 & 0.07 & 0.04 & -0.05 & -0.11 & 0.09 \\
Worried about debts & -0.04 & 0.06 & -0.08 & -0.01 & -0.01 & 0.04 & 0.04 \\
Winning and chasing & 0.09 & $0.17^{*}$ & 0.01 & 0.04 & -0.06 & -0.04 & 0.03 \\
Confidence in skill & 0.03 & 0.00 & -0.13 & 0.08 & -0.02 & -0.11 & -0.03 \\
CAMH-IGSTOT & 0.07 & 0.13 & -0.02 & 0.03 & -0.09 & -0.10 & 0.04 \\
\hline
\end{tabular}

$N S$ novelty seeking; $H A$ harm avoidance; $R D$ reward dependence; $P S$ persistence: $S D$ self directedness; $C O$ cooperativeness: $S T$ self transcendence: character factor

${ }^{*} p<.05 ; * * p<.01 ; * * * p<.001$

for DSM-IV-TR and SOGS-R scores (see Table 7), the correlation between impulsiveness and the UT and NEX was $\mathrm{r}_{\mathrm{p}}=.30, p<.001$ and $\mathrm{r}_{\mathrm{p}}=.24, p<.001$ respectively. NE also was significantly correlated with impulsiveness, $\mathrm{r}_{\mathrm{p}}=.30, p<.001$.

Hypothesis $4 \mathrm{~d}$ was that WC would be related to measures of erroneous beliefs. Scores on the REKT (Turner and Liu 1999; Turner et al. 2006) were negatively correlated with WC, $\mathrm{r}_{\mathrm{p}}=-.15, p<.01$. In addition, the GCQ persistence scale was most strongly correlated with WC, $\mathrm{r}_{\mathrm{p}}=.36, p<.001$ (see Table 7). These results are consistent with hypothesis $4 \mathrm{~d}$. WC was also correlated with GCQ rituals, $\mathrm{r}_{\mathrm{p}}=.33, p<.001$.

Hypothesis $4 \mathrm{e}$ was that CS would be correlated with GCQ systems. Consistent with hypothesis $4 \mathrm{e}$, the partial correlation of CS was substantially correlated with GCQ systems, $\mathrm{r}_{\mathrm{p}}=.45, p<.001$. Another interesting finding was that GCQ maintaining a positive attitude was most strongly associated with $\mathrm{CS}, \mathrm{r}_{\mathrm{p}}=.38, p<.001$, and $\mathrm{PE}, \mathrm{r}_{\mathrm{p}}=.35, p<.001$. In addition, the lowest correlations with GCQ positive attitude were for NE, CO and WD which are all negative affect situations thus providing some divergent validation for those scales. Of note also: CS and WC had the strongest correlations with GCQ thinking of rewards.

\section{The Temperament and Character Inventory (TCI)}

Table 8 lists the partial correlations between the TCI and the CAMH-IGS. After controlling for DSM-IV-TR and SOGS-R, there were significant partial correlations of TCI harm avoidance with NE, $\mathrm{r}_{\mathrm{p}}=.22, p<.05$ and CO, $\mathrm{r}_{\mathrm{p}}=.16, p<.05$ which are consistent with hypothesis $4 \mathrm{a}$ indicating that these scales measure anxiety. In addition, the TCI provided a useful instance of divergent validity in that cooperation (a measure of the concept of self as an integral part of humanity or society) had a significant negative partial correlated with $\mathrm{CO}, \mathrm{r}_{\mathrm{p}}=-.20, p<.05$. The zero order correlation was significant between novelty seeking and all of the CAMH-IGS subscales except for PE. However, contrary to hypothesis $4 \mathrm{c}$, the partial correlation of novelty 
seeking and UT was not significant. In fact none of the CAMH-IGS subscales had significant partial correlations with novelty seeking.

Sex and Sample Differences by Subscale (Hypotheses 5 \& 6)

In a general, female probable pathological gamblers scored higher than males on the CAMH-IGS; however, the difference between males and females only reached significance on NEX, $t=-2.0, p<.05$, and NE, $t=-2.2, p<.05^{3}$. The result with NE is consistent with hypothesis 5, but the result for NEX was not expected. As shown in Table 9, males and females are fairly similar on the CAMH-IGS. In addition, CS was significantly higher for males in both sub-clinical, $t=2.1, p<.05$, and non-problem, $t=3.7, p<.001$. Males scored higher than females. Male and female probable pathological gamblers did not differ on CS.

As a validity check, the subscales scores were compared across the three samples. Consistent with hypothesis 6 , the scales produced similar results for the three samples. For probable pathological gamblers, only one subscale-WD-differed significantly between the three samples, $\mathrm{F}(2,320)=8.9, p<.001$. People in the second sample $(\mathrm{M}=21$, $\mathrm{SD}=21)$ scored significantly lower than those in sample one $(\mathrm{M}=35, \mathrm{SD}=31)$ or sample three $(\mathrm{M}=31, \mathrm{SD}=23)$.

Not surprisingly, non-problem gamblers scored substantially lower than probable pathological gamblers on all subscales. However, only $29 \%$ of the non-problem gamblers scored zero on all subscales. The highest scores for non-problem gamblers was on PE, NEX, and SP. Very few non-problem gamblers endorsed any of the items on the WD or CO subscale.

\section{Discussion}

The CAMH-IGS is an assessment tool designed to measure a client's high risk situations for gambling. It can be used in treatment planning regardless of the theoretical background of the treatment agency. Consistent with hypothesis 1 , the factorial validity of the CAMH-IGS was demonstrated using confirmatory factor analysis. No major contradictions to the factor structure were found. However, 3 items were found to be non-significant in the confirmatory factor analysis. In addition, convergent and divergent validity was demonstrated for several of CAMH-IGS subscales.

\section{Factorial Validity}

The structure of the CAMH-IGS overall is similar to the IDTS and DTCQ, and six of the subscales from the IDTS were also used on the CAMH-IGS. In addition, the CAMH-IGS has four subscales that are more specifically related to gambling problems including NEX, WD, WC, and CS. The confirmatory factor analysis in general supported the 10-subscale theoretical structure of the CAMH-IGS.

In addition to the overall analysis, all of the CAMH-IGS subscales are reliable and unifactorial. For each subscale, the alpha was well above the .70 that is considered adequate for a reliability analysis. The factor analysis of each subscale indicates that a single factor accounts for half or more than half of the co-variance between items for each subscale.

\footnotetext{
${ }^{3}$ These sex finding should be treated as tentative because the significance level is only .05 and there are 8 scales being compared. The effect for NE was predicted apriori, but the effect of NEX is actually the opposite of what was predicted.
} 
Table 9 Differences between males vs. females and non-problem, problem gamblers and probable pathological gamblers on the CAMH-IGS $(N=522)$

\begin{tabular}{|c|c|c|c|c|c|c|c|c|c|c|c|c|}
\hline & \multicolumn{4}{|c|}{ Non-problem } & \multicolumn{4}{|c|}{ Sub-clinical problems } & \multicolumn{4}{|c|}{ Probable pathological } \\
\hline & \multicolumn{2}{|l|}{$\begin{array}{l}\text { Male } \\
n=108\end{array}$} & \multicolumn{2}{|c|}{$\begin{array}{l}\text { Female } \\
n=92\end{array}$} & \multicolumn{2}{|c|}{$\begin{array}{l}\text { Male } \\
n=43\end{array}$} & \multicolumn{2}{|c|}{$\begin{array}{l}\text { Female } \\
n=20\end{array}$} & \multicolumn{2}{|c|}{$\begin{array}{l}\text { Male } \\
n=174\end{array}$} & \multicolumn{2}{|c|}{$\begin{array}{l}\text { Female } \\
n=85\end{array}$} \\
\hline & M & $\mathrm{SD}$ & M & SD & M & $\mathrm{SD}$ & M & $\mathrm{SD}$ & M & SD & M & $\mathrm{SD}$ \\
\hline Negative emotions & 8 & 12 & 9 & 12 & 18 & 15 & 15 & 14 & $44^{*}$ & 23 & $50 *$ & 25 \\
\hline Conflict with others & 2 & 5 & 3 & 7 & 9 & 16 & 5 & 7 & 29 & 23 & 31 & 27 \\
\hline Urges and temptations & 16 & 17 & 13 & 15 & 29 & 20 & 25 & 18 & 50 & 22 & 55 & 23 \\
\hline Testing personal control & 7 & 12 & 7 & 12 & 14 & 16 & 13 & 16 & 37 & 21 & 41 & 26 \\
\hline Pleasant emotions & 30 & 29 & 24 & 25 & 41 & 24 & 39 & 19 & 55 & 22 & 58 & 22 \\
\hline Social pressure & 15 & 18 & 15 & 18 & 23 & 19 & 26 & 21 & 40 & 22 & 41 & 22 \\
\hline Need for excitement & 21 & 22 & 18 & 20 & 35 & 26 & 33 & 22 & $54 *$ & 22 & $60^{*}$ & 22 \\
\hline Worried about debts & 2 & 6 & 3 & 10 & 7 & 12 & 6 & 10 & 33 & 27 & 31 & 25 \\
\hline Winning and chasing & 12 & 15 & 11 & 16 & 25 & 16 & 24 & 16 & 49 & 22 & 55 & 23 \\
\hline Confidence in skill & $24 * * *$ & 26 & $12 * * *$ & 20 & $39^{*}$ & 25 & $26^{*}$ & 22 & 55 & 22 & 51 & 25 \\
\hline CAMH-IGSTOT & 13 & 13 & 11 & 13 & 23 & 15 & 20 & 14 & 44 & 18 & 47 & 20 \\
\hline
\end{tabular}

$* p<.05 ; * * * p<.001$

Asterisks indicate subscales where male-female differences reached univariate significance. Note that sex was missing in two data files so the sample size was 522, rather than 524

\section{Convergent Validity}

Convergent validity of the CAMH-IGS was also established in the present study through correlations of the CAMH-IGS subscales with external measures. Consistent with hypothesis 3, all of the CAMH-IGS subscales were correlated with SOGS-R and DSM-IV-TR-TR. UT, NE, and WC subscales were the most strongly related to gambling problems. The particularly strong correlations between DSM-IV-TR and NE and UT are consistent with previous work with the IDTS (Turner et al. 1997) and DTCQ (Sklar et al. 1997) that found strong correlations between the severity of addiction symptoms and unpleasant emotions and urges and temptations scales. However, it is important to note that gambling heavily in any of these situations may be an indicator of gambling problems.

Convergent and divergent validity of the subscales was established by showing that after controlling for SOGS-R and DSM-IV-TR several subscales were more strongly correlated to external variables that they were conceptually related to than to other external variables that they were not conceptually related to. Consistent with hypothesis $4 \mathrm{a}, \mathrm{NE}$ and $\mathrm{CO}$ were both significantly correlated with depression, anxiety, and TCI harm avoidance indicating that these subscales are related to negative affect. This is consistent with previous studies that have argued that gambling is often motivated by a need to escape from negative emotions (Jacobs 1986; Gupta and Derevensky 1998a, 1998b). In contrast PE, CS and TPC were not related to these variables. In addition, $\mathrm{CO}$ had a negative partial correlation with TCI cooperativeness indicating that $\mathrm{CO}$ is also detecting interpersonal problems. This finding indicates divergent validity between $\mathrm{NE}$ and $\mathrm{CO}$.

However, consistent with hypothesis $4 \mathrm{~b}$, PE scores were not correlated with depression or anxiety. Nonetheless PE was significantly correlated with DSM-IV-TR scores, $r=.54$, 
$p<.001$. In addition, the PE mean score (see Table 9) was one of the highest average scores for both male and female probable pathological gamblers. This finding is important because it indicates that people do not simply gamble to avoid unpleasant emotions; some people report being triggered to gamble when in a positive mood state (e.g., "happy").

We were also able to demonstrate convergent validity for several other subscales. For example, consistent with hypothesis 4c, UT was most strongly correlated with impulsivity. Consistent with hypothesis 4d, WC was significantly correlated with the REKT and GCQ persistence, indicating that WC taps into erroneous beliefs. Consistent with hypothesis $4 \mathrm{e}$, CS was significantly correlated with the use of strategies and systems as measured by the GCQ Skill. In addition, the unexpected finding that GCQ positive attitude had strong partial correlations with PE and CS but very small partial correlations with $\mathrm{NE}, \mathrm{CO}$ and WD provides further evidence for divergent validity of these scales.

Overall, these patterns of partial correlations indicate that the subscales of the CAMHIGS can identify individual differences in self-reported situational risk for gambling. From a clinical point of view, the specific triggers are useful because they clarify the nature of the individual client's problems. For example, a high score on CO may suggest problems with interpersonal relationships, whereas a high score on NE may indicate a mood disorder. The CAMH-IGS is as long as it is, precisely to provide this sort of in-depth information, which may be clinically useful. Overall in this study, the CAMH-IGS has been shown to be a valid means of determining the situational risk profile for different problem gamblers.

\section{Sex and Sample Differences}

The CAMH-IGS appears to be very similar for males and females. Only two subscales- $\mathrm{NE}$ and NEX - showed significant sex differences. In both cases female probable pathological gamblers scored higher than male probable pathological gamblers. The higher score on NE was expected based on previous work with the IDTS and DTCQ and confirms hypothesis 5 (Annis et al. 1996b, 1996c). This finding indicates that females are more likely to report engaging in an addictive behavior to escape negative emotions. However, the sex difference for NEX was not expected. Rather it was expected that male action gamblers would score higher on NEX. These sex differences were small and may simply be random fluctuations. The results should be treated as tentative until replicated. Another finding was that although males scored significantly higher than females on CS amongst non-problem gamblers and sub-clinical problem gamblers, there was no sex difference on CS for probable pathological gamblers.

Finally, consistent with hypothesis 6 , it was shown that the samples were similar in spite of the different collection methods used.

\section{Limitations}

One limitation of the current study was that the data was collected using a variety of different types of administration of the IGS. In addition, the participants were recruited using a variety of methods including newspaper ads, advertisement at our treatment centre and snowball techniques (asking participants to refer additional participants to the study). Furthermore, all three samples used in the analyses were voluntary community samples. The inclusion of voluntary community members may introduce some bias into the sampling. For example, people who respond to advertisements may be different from those who do not. Further study is needed to confirm the findings and determine if changes in the setting (e.g., online vs. paper and pencil) or sampling method result in differences in the results on the CAMH- 
IGS. An additional limitation was the sample size. Although adequate for the analyses conducted, the sample size is too small for a more detailed analysis comparing the factor structures for subtypes of gamblers.

\section{Conclusion}

In conclusion no major contradictions to the factor structure were found in these analyses. However, 3 loadings were found to be non-significant in the confirmatory factor analysis. In future revisions to the IGS these items and all cross-loaded items may be removed to clean up the factor structure. In addition, convergent and divergent validity was demonstrated for several of CAMH-IGS subscales. The CAMH-IGS is available on the internet free of charge: www.problemgambling.ca/EN/ResourcesForProfessionals/Pages/IGS.aspx

Information about how to use and interpret the CAMH-IGS can be found in LittmanSharp et al. (2009) which is available at the same web site. Additional data are currently being collected from the online CAMH-IGS application. In the near future this data will be examined to determine if this application (on-line) results in the same, or a different pattern of results. Preliminary results are consistent with the model presented in this paper.

Funding Parts of these studies were supported in past by grants from the National Centre for Responsible Gaming (NCRG), Ontario Problem Gambling Research Centre (OPGRC), and the Ontario Ministry of Health and Long Term Care (MOHLTC). The views expressed here do not necessarily reflect those of CAMH, MOHLTC, OPGRC, or the NCRG.

\section{References}

American Psychiatric Association. (2000). Diagnostic and statistical manual of mental disorders: Fourth edition, text revision (DSM-IV-TR). Washington, DC: American Psychiatric Association.

Annis, H. M. (1982). Inventory of drinking situations. Toronto: Addiction Research Foundation of Ontario.

Annis, H. M. (1990). Effective treatment for drug and alcohol problems: what do we know? Forum on Corrections Research, 2, 18-23.

Annis, H. M., \& Davis, C. S. (1989). Relapse prevention. In R. K. Hester \& W. R. Miller (Eds.), Handbook of alcoholism treatment approaches (pp. 170-182). New York: Pergamon Press.

Annis, H. M., \& Graham, J. M. (1988). Situational Confidence Questionnaire (SCQ) users guide. Toronto: Addiction Research Foundation of Ontario.

Annis, H. M., \& Graham, J. M. (1995). Profile types on the inventory of drinking situations: implications for relapse prevention counselling. Psychology of Addictive Behaviours, 9, 176-182.

Annis, H. M., \& Martin, G. (1985). Inventory of drug-taking situations. Toronto: Addiction Research Foundation of Ontario.

Annis, H. M., Graham, J. M., \& Davis, C. S. (1987). Inventory of Drinking Situations (IDS) users guide. Toronto: Addiction Research Foundation of Ontario.

Annis, H. M., Schober, R., \& Kelly, E. (1996a). Matching addiction outpatient counseling to client readiness for change: the role of structured relapse prevention counseling. Experimental and Clinical Psychopharmacology, 4, 37-45.

Annis, H. M., Sklar, S. M., \& Turner, N. E. (1996b). Drug-Taking Confidence Questionnaire (DTCQ): Users guide. Toronto: Addiction Research Foundation of Ontario.

Annis, H. M., Turner, N. E., \& Sklar, S. M. (1996c). Inventory of drug-taking situations: Users guide. Toronto: Addiction Research Foundation of Ontario.

Barrat, E. S. (1987). Impulsiveness and anxiety: information processing and electroencephalograph topography. Journal of Research in Personality, 21, 453-463. 
Byrne, B. M. (1989). A primer of LISREL. Basic applications and programming for confirmatory factor analytic models. New York: Springer.

Cloninger, C. R., Przybeck, T. R., Svrakic, D. M., \& Wetzel, R. D. (1994). The temperament and character inventory (TCI): A guide to its development and use. St Louis: Center for Psychobiology of Personality.

Ferentzy, P., \& Turner, N. E. (2013). A history of problem gambling: Temperance, substance abuse, medicine and metaphors. New York: Springer.

George, D., \& Mallery, P. (2003). SPSS for Windows step by step: A simple guide and reference. 11.0 update (4th ed.). Boston: Allyn \& Bacon.

Grant, J.E. (2013). From "Pathological Gambling" to "Gambling Disorder:" Changes in the DSM-5. Retrieve May 2013 from http://blog.ncrg.org/blog/2013/04/evolving-definition-pathological-gambling-dsm-5

Gupta, R., \& Derevensky, J. L. (1998a). Adolescent gambling behavior: a prevalence study and examination of the correlates with problem gambling. Journal of Gambling Studies, 14, 319345 .

Gupta, R., \& Derevensky, J. L. (1998b). An empirical examination of Jacobs' general theory of addictions: do adolescent gamblers fit the theory? Journal of Gambling Studies, 14, 17-50.

Jaccard, J., \& Wan, C. K. (1995). Measurement error in the analysis of interaction effects between continuous predictors using multiple regression: multiple indicator and structural equation approaches. Psychological Bulletin, 117, 348-357.

Jacobs, D. F. (1986). A general theory of addictions: a new theoretical model. Journal of Gambling Behavior, $2,15-31$.

Jöreskog, K. G., \& Sörbom, D. (1993). LISREL 8. User's Reference Guide. Chicago: Scientific Software International.

Kose, S. (2003). Psychobiological model of temperament and character: TCI [online version]. Yeni Symposium, 41(2), 86-97. Retrieved 18 October 2006 from http://www.yenisymposium.net/ FULLTEXT/2003(2)/ys2003_41_2_6.pdf

Leary, M. R. (1983). Social anxiousness: the construct and its measurement. Journal of Personality Assessment, 47, 66-75.

Lesieur, H. R., \& Blume, S. B. (1987). The South Oaks Gambling Screen (SOGS): a new instrument for the identification of pathological gamblers. The American Journal of Psychiatry, 144(9), 1184-1188.

Lesieur, H. R., \& Blume, S. B. (1993). Revising the South Oaks Gambling Screen in different settings. Journal of Gambling Studies, 9, 213-233.

Littman-Sharp, N. (1997). Unpublished raw data.

Littman-Sharp, N., \& Stirpe, T. (1996). The inventory of gambling situations: A preliminary report on a riskassessment instrument. Chicago: Paper presented at the annual conference of the National Council on Compulsive Gambling.

Littman-Sharp, N., Turner, N.E. \& Toneatto, T. (2009). Inventory of gambling situations: Users Guide. Toronto: CAMH. Available at http://www.problemgambling.ca/EN/ResourcesForProfessionals/Pages/IGS.aspx

MacCallum, R. C., Widaman, K. F., Zhang, S., \& Hong, S. (1999). Sample size in factor analysis. Psychological Methods, 4(1), 84-99.

MacCallum, R. C., Widaman, K. F., Preacher, K. J., \& Hong, S. (2001). Sample size in factor analysis: the role of model error. Multivariate Behavioral Research, 36(4), 611-637.

Marlatt, G. A. (1978). Craving for alcohol, loss of control and relapse: A cognitive-behavioral analysis. In P. E. Nathan, G. A. Martatt, \& T. Løberg (Eds.), Alcoholism: New directions in behavioral research and treatment (pp. 271-314). New York: Plenum Press.

Marlatt, G. A. (1979a). Alcohol use and problem drinking: A cognitive-behavioral analysis. In P. C. Kendall \& S. D. Hollon (Eds.), Cognitive-behavioral interventions: Theory, research and procedures (pp. 319355). New York: Academic.

Marlatt, G. A. (1979b). A cognitive-behavioral model of the relapse process. In N. A. Krasnegor (Ed.), Behavioral analysis and treatment of substance abuse (pp. 191-200). Rockville: National Institute on Drug Abuse Research Monograph, 25.

Marlatt, G. A. (1985). Situation determinants of relapse and skill-training interventions. In G. A. Marlatt \& J. R. Gordon (Eds.), Relapse prevention: Maintenance strategies in the treatment of addictive behaviours. New York: Guilford.

Marlatt, G. A., \& Gordon, J. R. (1980). Determinants of relapse: Implications for the maintenance of behaviour change. In P. O. Davidson \& S. M. Davidson (Eds.), Behavioral medicine: Changing health lifestyles (pp. 410-452). New York: Brunner-Mazel.

Marsh, H. W., Balla, J. R., \& McDonald, R. P. (1988). Goodness-of-fit indexes in confirmatory factor analysis: the effect of sample size. Psychological Bulletin, 103, 391-410.

Nunnally, J. C. (1978). Psychometric theory (2nd ed.). New York: McGraw-Hill. 
Petry, N. M., Rash, C. J., \& Blanco, C. (2010). The inventory of gambling situations in problem and pathological gamblers seeking alcohol and drug abuse treatment. Experimental and Clinical Psychopharmacology, 18(6), 530-538.

Potenza, M. N. (2008). The neurobiology of pathological gambling and drug addiction: an overview and new findings. Philosophical Transactions of the Royal Society B: Biological Sciences, 363(1507), 3181-3189.

Preston, D. L., McAvoy, S., Saunders, C., Gillam, L., Saied, A., \& Turner, N. E. (2012). Problem gambling and mental health co-morbidity in Canadian federal offenders. Criminal Justice and Behavior, 39(10), 1373-1388.

Radloff, L. S. (1977). The CES-D scale: a self-report depression scale for researcher in the general population. Applied Psychological Measurement, 1, 385-401.

Robinson, J. P., Shaver, P. R., \& Wrightsman, L. S. (1991). Measures of personality and social psychological attitudes. Toronto: Academic.

Room, R., Turner, N. E., \& Ialomiteanu, A. (1999). Community effects of the opening of the Niagara Casino: a first report. Addiction, 94, 1449-1466.

Sklar, S. M., \& Turner, N. E. (1999). A brief measure for the assessment of coping self-efficacy among alcohol and other drug users. Addiction, 94, 723-729.

Sklar, S. M., Annis, H. M., \& Turner, N. E. (1997). Development of the drug-taking confidence questionnaire: a measure of coping self-efficacy. Addictive Behaviors, 22, 655-670.

Sklar, S. M., Annis, H. M., \& Turner, N. E. (1998). Group comparisons of coping self-efficacy between alcohol and cocaine abusers seeking treatment. Psychology of Addictive Behaviors, 13(2), 123-133.

Toneatto, T. (1997). Unpublished raw data.

Toneatto, T. (1998). Gambling behavior questionnaire. (Unpublished Questionnaire).

Toneatto, T., Blitz-miller, T., Calderwood, K., Dragonetti, R., \& Tsanos, A. (1997). Cognitive distortions in heavy gambling. Journal of Gambling Studies, 13, 253-266.

Turner, N.E. (1997). Robustness properties of polychoric correlation for ordinal variables. Poster presented at the 1997 American Psychological Association conference.

Turner, N. E., \& Liu, E. (1999). The naive human concept of random events. Boston: Paper presented at the conference of the American Psychological Association.

Turner, N.E. \& McKenzie, B. (2001). Unpublished raw data.

Turner, N.E. \& Toneatto, T. (1999), Unpublished raw data.

Turner, N.E. \& Toneatto, T. (2001), Unpublished raw data.

Turner, N. E., Annis, H. M., \& Sklar, S. M. (1997). Measurement of antecedents of drug use and drinking: psychometric properties of the Inventory of Drug Taking Situations (IDTS). Behavior Research and Therapy, 35, 465-483.

Turner, N., Littman-Sharp, N., \& Zangeneh, M. (2006). The experience of gambling and its role in problem gambling. International Gambling Studies, 6, 237-266.

Turner, N. E., Jain, U., Spence, W., \& Zangeneh, M. (2008). Pathways to pathological gambling: component analysis of variables related to pathological gambling. International Gambling Studies, 8(3), 281-298.

Turner, N. E., Preston, D. L., Saunders, C., McAvoy, S., \& Jain, U. (2009). The relationship of problem gambling to criminal behaviour in a sample of Canadian male federal offenders. Journal of Gambling Studies, 25, 153-169.

Turner, N. E., Liu, E., \& Toneatto, T. (2011). What does a random line look like: an experimental study. International Journal of Mental Health and Addiction, 9, 60-71. doi:10.1007/s11469-009-9251-z.

Weiss, L. M., \& Petry, N. M. (2008). Psychometric properties of the inventory of gambling situations with a focus on gender and age differences. The Journal of Nervous and Mental Disease, 196, 321-328. 